\title{
Photocurrent response of phloxin B-cetyltrimethylammonium bromide photogalvanic cell device
}

\author{
K.R. GENWA*, SHRADDHA \\ Department of Chemistry, J.N.V. University, Jodhpur, India
}

\begin{abstract}
Photocurrent and photovoltage generation using phloxin B dye in aqueous and micellar medium at different concentrations have been studied in a photogalvanic cell. The photopotential and photocurrent generated were $1135.0 \mathrm{mV}$ and $260.0 \mu \mathrm{A}$, respectively. The observed solar energy conversion efficiency with CTAB surfactant was $0.64 \%$ and maximum power of the cell was $66.72 \mathrm{~mW}$. The output of the cell was sensitive to various parameters, like dye concentration, reductant concentration, $\mathrm{pH}$, light intensity, electrode area and diffusion length. Current-potential characteristics studied by I-V curve of the cell and the mechanism of cell photovoltage generation have been presented in the paper.
\end{abstract}

Keywords: phloxin B; CTAB; fill factor; conversion efficiency; photogalvanic cell

(C) Wroclaw University of Technology.

\section{Introduction}

Solar electromagnetic energy can be converted by photovoltaic or other processes into electrical energy which can then be stored in a capacitor or in electrical batteries. Solar energy can be converted into electricity by photovoltaic and photogalvanic cell systems. In a photovoltaic cell a semiconductor material emits photoelectrons directly, whereas in a photogalvanic cell photosensitizing dye gives and takes electrons. The efficiency of solar photovoltaic cells is quite high and photovoltaic technology is fully developed, whereas the efficiency of photogalvanic cells is low due to intermediate reactions involved in conversion of solar energy into electrical energy and photogalvanic technology still needs practical implementation. Further, photovoltaic technology is costly and needs external storage devices for power storage as it lacks inherent storage capacity. Photogalvanic technology is cheap and has inherent storage capacity. Photogalvanic cell is a device in which light is absorbed within a highly absorbing electrolyte to provide energy for redox reaction and electric energy is generated by subsequent charge transfer to the

*E-mail: krg2004@rediffmail.com electrolyte by redox process. Photogalvanic cells are based on photogalvanic effect [1-4]. This effect was studied using an aqueous ethylene blue Ni mesh by Bayer et al. [6], whereas Markov et al. [5, 7] reported photopotential and photocurrent generation by aqueous aliphatic alcohol and salt. A new photogalvanic cell was reported by Jana [8]. Hamdi and Aliwi [9] observed phogalvanic effect in $\mathrm{Fe}$ (II)-beta-diketonate/thionine systems in aqueous acetonitrile. Later, some interesting photogalvanic systems were reported by various workers [10-14]. Recently, we have reported some new and relatively efficient photogalvanic systems with a reasonable amount of electrical output and storage capacity [15-17].

A detailed review of literature reveals that many workers have reported the studies on harvesting the solar energy in various forms of solar cells. Various dyes and surfactants have been used in photogalvanic cells but energy conversion of photogalvanic cell is still low. In order to reach a significant value of conversion efficiency and storage capacity, the present system, i.e. phloxin B-CTAB-EDTA system has been subjected to detailed studies. Systematic studies of a cell consisting of phloxin B dye and surfactant redox couple have been carried out. All important cell characteristics have been 
reported here along with the mechanism of photovoltage generation in solution phase cell.

\section{Materials and method}

The phloxin B dye, obtained from Ases, Jodhpur, ethylenediaminetetraacetic acid, cetyltrimethylammonium bromide of AR grade, Loba Chemie, Mumbai, and sodium hydroxide from RFCL, New Delhi were used in the present work. Stock solutions were prepared in double distilled water. Stock solution of phloxin B dye $\left(4.4 \times 10^{-4} \mathrm{M}\right)$, reductant EDTA $\left(2.20 \times 10^{-3} \mathrm{M}\right)$, surfactant CTAB $\left(1.5 \times 10^{-3} \mathrm{M}\right)$ were used and $1 \mathrm{M} \mathrm{NaOH}$ was added for maintaining $\mathrm{pH}$ in alkaline range. During preparation of the dye solution the precaution was taken to protect the solution from light and to store it in a darkened container. $25 \mathrm{~mL}$ of a mixture having a known volume of dye, reductant, surfactant and $\mathrm{NaOH}$ was taken into a blackened $\mathrm{H}$ shaped glass tube. A platinum foil electrode $\left(1 \mathrm{~cm}^{2}\right)$ was immersed in one limb of the cell container containing a transparent window. The counter electrode SCE was placed in another limb. The $\mathrm{pH}$ of the solution was adjusted and measured by a $\mathrm{pH}$ meter.

When the cell attained a stable potential in dark, the platinum foil electrode was exposed to light source (tungsten lamp). A water filter was placed between the light source and the cell to cut-off thermal radiation. Electrical output of the cell - potential and current - were measured with $\mathrm{pH}$ meter and microammeter, respectively. The I-V characteristics of the cell were also studied by applying an external load in a form of a variable resistor in the microammeter circuit. The experimental setup and circuit are shown in Fig. 1.

\subsection{Variation of photovoltage and current}

The potential generated in the photogalvanic cell was found to change with time. Initially, the photogalvanic cell was placed in dark till it attained a stable potential and then the platinum electrode was exposed to the tungsten lamp. It was observed that the potential increased on illumination, which was due to the increase in electrons donating the

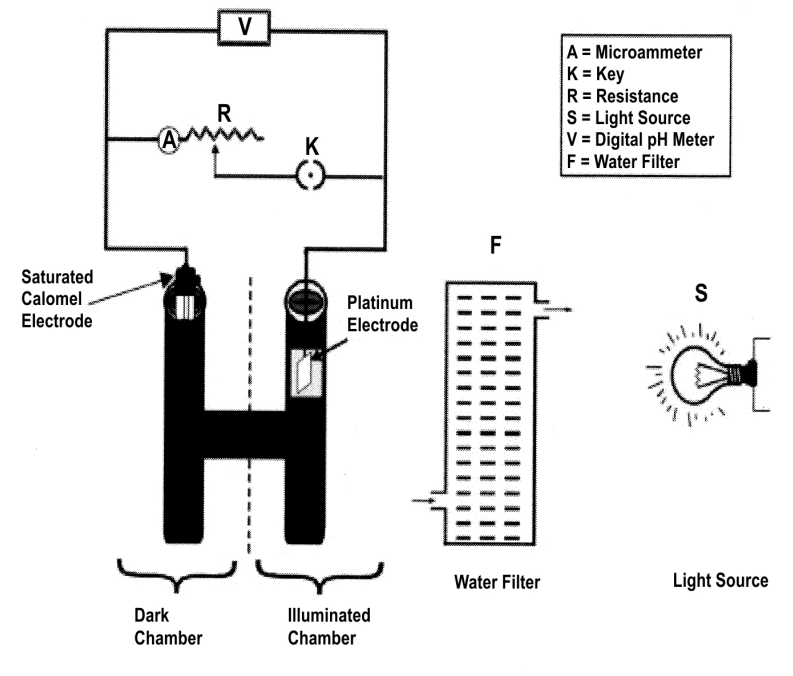

Fig. 1. Experimental set up with electrical circuit [17].

excited dye molecules during illumination, and it reached a maximum constant value after a certain period. This maximum potential is termed $\mathrm{V}_{\max }$. At $V_{\max }$ the number of excited dye molecules and electron donating the dye molecules was the highest. When the light source was removed, the direction of potential was reversed and a stable potential was again obtained after some time (Fig. 2). There was a rapid rise in the photocurrent of the photogalvanic cell on illumination and it reached a maximum value within few minutes. This maximum value of current was denoted by $\mathrm{i}_{\max }$. The current was found to decrease gradually with the period of illumination and finally reached a constant value at equilibrium. This value is represented as $i_{e q}$ in Fig. 3. After that the current was found to decrease on removing the source of illumination (Fig. 3).

\subsection{Study of absorption properties of pure phloxin $B$ and phloxin $B+C T A B$.}

Absorption spectra were recorded using systronics spectrophotometer 106 with a matched pair of silica cuvettes. Phloxin B showed an absorption peak in the visible region at $545 \mathrm{~nm}$. The concentration of the dye solution was kept at $4.4 \times 10^{-4} \mathrm{M}$ in all the experiments. Absorption spectra of the dye-surfactant combination, phloxin B-CTAB, were also taken. The value of absorbance increased with increasing CTAB concentration in 


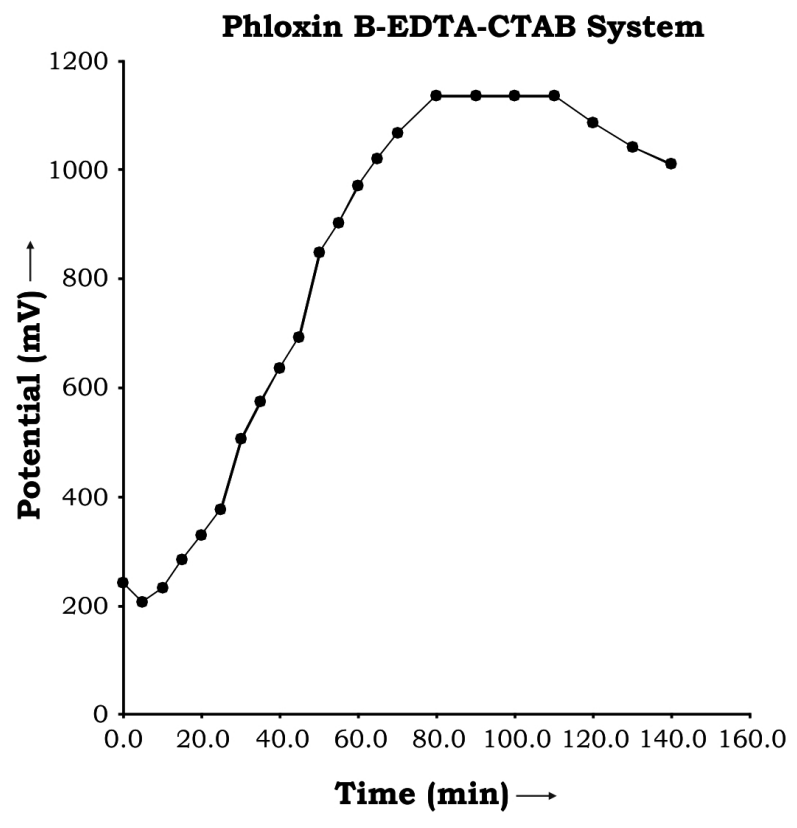

Fig. 2. Variation of potential with time.

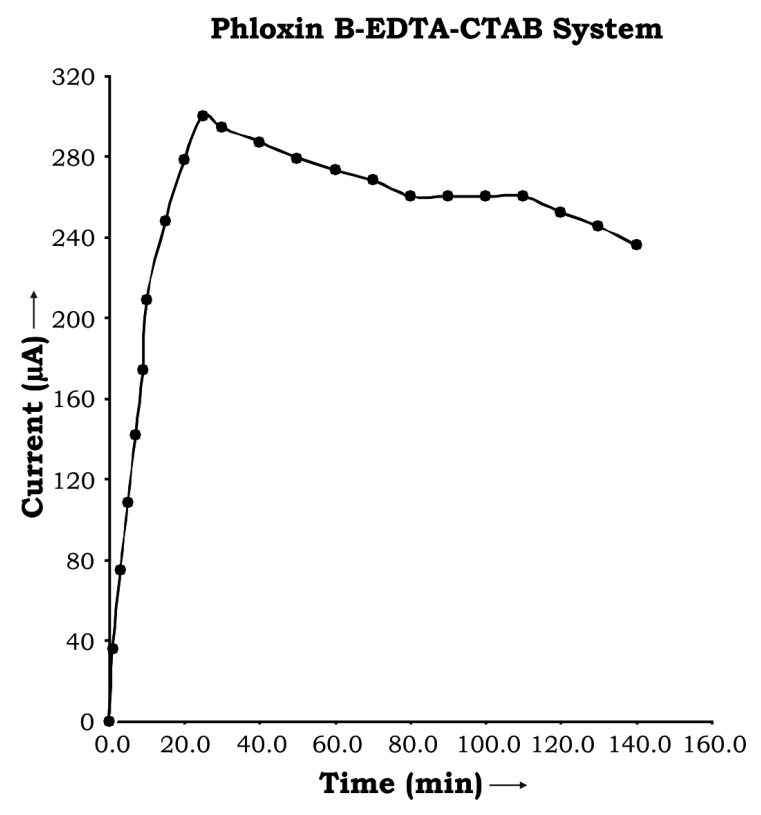

Fig. 3. Variation of current with time.

in the phloxin $\mathrm{B}$ solution and it reached its maximum value at $1.5 \times 10^{-3} \mathrm{M} \mathrm{CTAB} \mathrm{(Fig.} \mathrm{4).}$

\subsection{Mechanism of photovoltage and pho- tocurrent generation in a cell}

According to photochemistry of dyes in solution, chemically reactive species is the dye in the

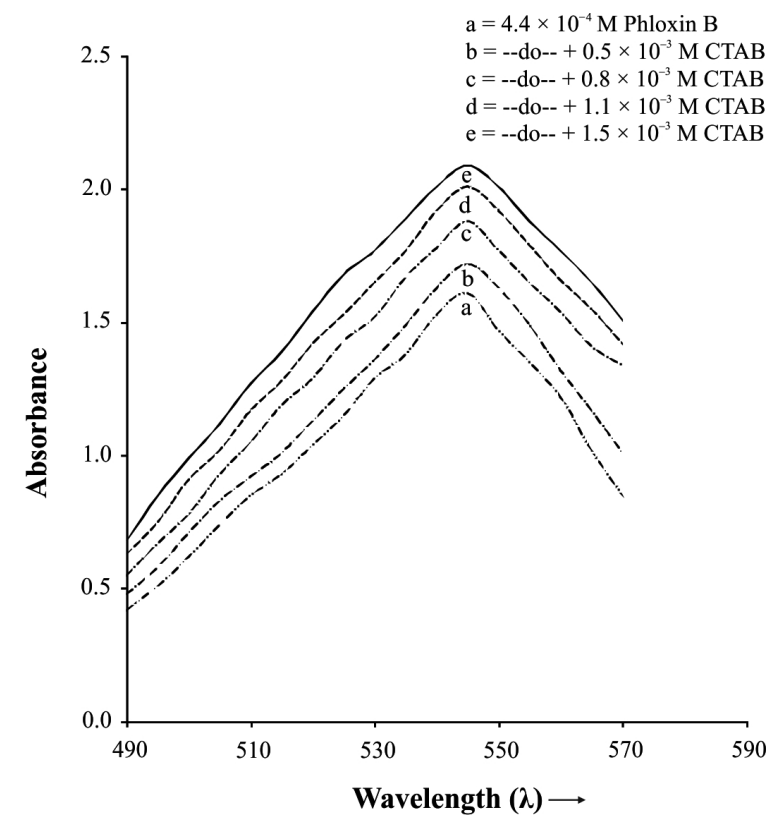

Fig. 4. Absorption spectra of photosensitizer.

triplet state. In particular, when certain dyes are excited by light in the presence of electron donating substances, the dyes are rapidly changing into colorless ("reduced") form. The dye is now a powerful reducing agent and donates electrons to other substances, while it returns to its oxidized state. Photovoltage and photocurrent generation in photogalvanic cell can be explained by the following mechanism schemes:

$$
\begin{aligned}
& \text { Illuminated chamber } \\
& \underset{\text { (Ground state) }}{D y e} \stackrel{h v}{\longrightarrow} \underset{\text { (First excited state) }}{D y e^{*}} \longrightarrow \underset{\text { (Triplet state) }}{D y e^{\prime}} \\
& D y e^{\prime}+R \longrightarrow \underset{(\text { semi or leuco form of dye })}{D y e^{-}+R^{+}}
\end{aligned}
$$

At platinum electrode:

$$
\text { Dye } e^{-} \longrightarrow \text { Dye }+e^{-}
$$

\section{Dark chamber}

At counter electrode, SCE:

$D y e+e^{-} \longrightarrow D y e^{-}$(semi or leuco form of dye) 


$$
D y e^{-}+R^{+} \longrightarrow D y e+R
$$

where Dye, Dye*, Dye ${ }^{-}, \mathrm{R}$ and $\mathrm{R}^{+}$represent the phloxin $\mathrm{B}$ dye, its excited form, reduced form, reductant EDTA, and oxidized form of reductant, respectively. The triplet state being relatively more stable than the singlet state plays a role in storage performance. The scheme of the mechanism is shown in Fig. 5 [18].

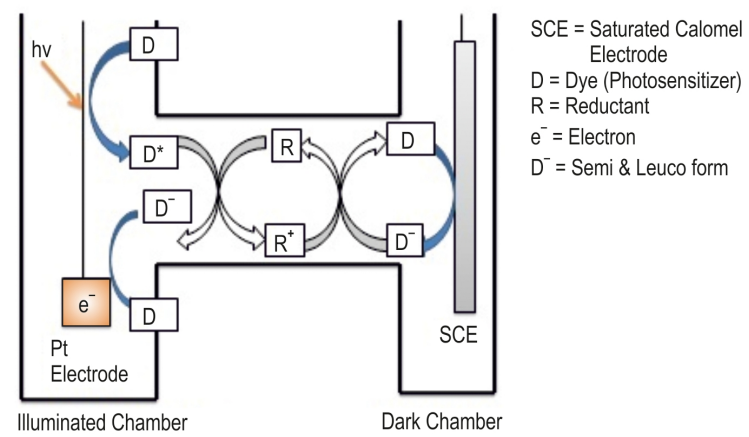

Fig. 5. Schematic representation of cell reactions.

\section{Results and discussion}

3.1. Effects of dye (phloxin B), reductant (EDTA) and surfactant (CTAB) concentration

Experimental results at various dye, reductant and surfactant concentrations are summarized in Table 1.

To improve the efficiency of a system a particular dye concentration should be chosen. The phloxin B-EDTA-CTAB system showed the best efficiency at the dye concentration of $4.4 \times 10^{-4} \mathrm{M}$. It was observed that as the dye concentration was increased, the photopotential and photocurrent increased to a maximum value and decreased on further increase in dye concentration. At low concentration of dye there was low availability of dye molecules to excite and donate electrons to the platinum electrode, whereas at higher concentration of dye, density of dye molecules in the path of platinum electrode was high and, therefore, they absorbed a major portion of light which resulted in the high electrical output.
With an increase in reductant concentration the electrical output increased and reached a maximum value at a particular concentration of reductant, equal to $2.20 \times 10^{-3} \mathrm{M}$. On further increase of reductant concentration the electrical output decreased because fewer reductant molecules were available for electron donation. The cell output increased with an increase in CTAB concentration but after achieving a particular value, the output of the cell started decreasing. The maximum was obtained at a CTAB concentration of $1.5 \times 10^{-3} \mathrm{M}$. In absence of CTAB, some decrease in electrical output was also observed. It indicates the presence of the charge transfer interaction between the dye and surfactant. The photoejection of electrons from dye-surfactant system depends on the charge on micelle.

\subsection{Effect of $\mathrm{pH}$ variation}

It was observed that the photopotential and photocurrent of the phloxin B-EDTA-CTAB system increased with $\mathrm{pH}$ and reached the maximum at $\mathrm{pH}$ $=12.64$ and then decreased with a further increase of $\mathrm{pH}$ value. It was found that the optimum electrical output obtained at a particular $\mathrm{pH}$ value might be caused by better availability of reductant donors formed at that $\mathrm{pH}$ value.

It was also observed that in an acidic medium the efficiency of the cell was poor. It might be due to proton attachment to the dye and reductant molecules, which resulted in poor electron donating power of the dye and reductant molecules to the platinum electrode. On the other hand, in an alkaline medium, the anions formation in the dye and reductant enhanced the electron donating power of the dye. The results showing the effect of $\mathrm{pH}$ on photopotential and photocurrent are summarized in Table 2.

\subsection{Effect of diffusion length}

The photogalvanic cell consisted of a platinum foil electrode and a saturated calomel electrode immersed in a two limb $\mathrm{H}$ shaped glass tube filled with solution. Diffusion length is a distance between these two electrodes. The cell's current parameters were studied by variation of 
Table 1. Effects of variation of phloxin B, EDTA and CTAB concentration.

\begin{tabular}{|c|c|c|}
\hline Concentration & Photopotential (mV) & Photocurrent $(\mu \mathrm{A})$ \\
\hline \multicolumn{3}{|c|}{$\left[\right.$ phloxin B] $\times 10^{-4} \mathrm{M}$} \\
\hline 4.37 & 772.0 & 195.0 \\
\hline 4.42 & 815.0 & 214.0 \\
\hline 4.46 & 852.0 & 242.0 \\
\hline 4.40 & 894.0 & 260.0 \\
\hline 4.54 & 855.0 & 237.0 \\
\hline 4.59 & 809.0 & 212.0 \\
\hline 4.64 & 770.0 & 193.0 \\
\hline \multicolumn{3}{|l|}{$[$ EDTA $] \times 10^{-3} \mathrm{M}$} \\
\hline 1.88 & 772.0 & 194.0 \\
\hline 1.92 & 814.0 & 214.0 \\
\hline 1.96 & 852.0 & 242.0 \\
\hline 2.00 & 894.0 & 260.0 \\
\hline 2.04 & 847.0 & 237.0 \\
\hline 2.08 & 802.0 & 212.0 \\
\hline 2.12 & 767.0 & 190.0 \\
\hline \multicolumn{3}{|l|}{$[\mathrm{CTAB}] \times 10^{-3} \mathrm{M}$} \\
\hline 1.38 & 762.0 & 189.0 \\
\hline 1.42 & 804.0 & 206.0 \\
\hline 1.46 & 843.0 & 234.0 \\
\hline 1.50 & 894.0 & 260.0 \\
\hline 1.55 & 851.0 & 229.0 \\
\hline 1.59 & 802.0 & 207.0 \\
\hline 1.64 & 766.0 & 185.0 \\
\hline
\end{tabular}

Table 2. Effect of variation of $\mathrm{pH}$.

\begin{tabular}{ccc}
\hline $\mathrm{pH}$ & Photopotential $(\mathrm{mV})$ & Photocurrent $(\mu \mathrm{A})$ \\
\hline \hline 12.52 & 777.0 & 199.0 \\
12.56 & 818.0 & 218.0 \\
12.60 & 857.0 & 245.0 \\
12.64 & 894.0 & 260.0 \\
12.68 & 851.0 & 242.0 \\
12.72 & 814.0 & 215.0 \\
12.76 & 772.0 & 194.0 \\
\hline$\left[\right.$ phloxin B] $=4.4 \times 10^{-4} \mathrm{M}$ & & Light intensity $=10.4 \mathrm{~mW} \cdot \mathrm{cm}^{-2}$ \\
{$[$ EDTA $]=2.24 \times 10^{-3} \mathrm{M}$} & & Temp. $=303 \mathrm{~K}$ \\
{$[$ CTAB $]=1.5 \times 10^{-3} \mathrm{M}$} & &
\end{tabular}

diffusion length using $\mathrm{H}$-shaped containers of different dimensions.

It was observed that the maximum photocurrent $\left(\mathrm{I}_{\max }\right)$ and the rate of initial generation of the current increased regularly with an increase in diffusion length but the equilibrium photocurrent remained unaffected. The current generation in the cell resulted from the flow of electrode active species produced in the cell reaction. The results are summarized in Table 3.

\subsection{Effect of electrode area}

The current generation of the phloxin B-EDTA-CTAB system was also studied by 
Table 3. Effect of variation of diffusion length.

\begin{tabular}{cccc}
\hline $\begin{array}{c}\text { Diffusion length } \\
\mathrm{D}_{\mathrm{L}}(\mathrm{mm})\end{array}$ & $\begin{array}{c}\text { Maximum photocurrent } \\
\mathrm{I}_{\max }(\mu \mathrm{A})\end{array}$ & $\begin{array}{c}\text { Equilibrium } \\
\text { photocurrent } \\
\mathrm{I}_{\mathrm{eq}}(\mu \mathrm{A})\end{array}$ & $\begin{array}{c}\text { Rate of initial generation of } \\
\text { current } \\
\left(\mu \mathrm{A} \cdot \mathrm{min}^{-1}\right)\end{array}$ \\
\hline \hline 30.0 & 288.0 & 272.0 & 8.23 \\
35.0 & 292.0 & 268.0 & 8.34 \\
40.0 & 296.0 & 264.0 & 8.46 \\
45.0 & 300.0 & 260.0 & 8.57 \\
50.0 & 305.0 & 256.0 & 8.71 \\
55.0 & 309.0 & 254.0 & 8.97 \\
60.0 & 314.0 & 250.0 & \multicolumn{2}{c}{ Light intensity $=10.4 \mathrm{~mW} \cdot \mathrm{cm}^{-2}$} \\
{$[$ Thloxin $\mathrm{B}]=4.4 \times 10^{-4} \mathrm{M}$} & \multicolumn{2}{c}{$\mathrm{pH}=12.64 \mathrm{~K}$} \\
{$[$ EDTA $]=2.20 \times 10^{-3} \mathrm{M}$} & \multicolumn{2}{c}{}
\end{tabular}

varying the area of platinum electrode. It was observed that with increasing the electrode area, $\mathrm{I}_{\max }$ regularly increased but $\mathrm{I}_{\mathrm{eq}}$ negligibly decreased. The effects of variation in electrode area on the maximum and minimum photocurrent values are shown in Table 4.

\subsection{Effect of light intensity}

Effects of variation of light intensity on photopotential and photocurrent were studied using a solarimeter. It was found that the photocurrent showed a linearly increasing behavior with an increase in light intensity, whereas the photopotential increased in a logarithmic manner. The increase in the light intensity increased the number of photons per unit area (incident power) falling on the dye molecules around the platinum electrode and, therefore, an increase in the electrical output was observed. The results are given in Table 5 .

\subsection{Cell current-voltage characteristics, storage performance and conversion effi- ciency}

The cell I-V characteristics showed inversely proportional relation between current and potential. The open circuit voltage and the short circuit voltage of the system were measured under the continuous illumination with light using a digital $\mathrm{pH}$ meter (keeping the circuit open) and a microammeter (keeping the circuit closed), respectively. In $\mathrm{I}-\mathrm{V}$ curve we obtained a point, where the product of the current and potential was maximum (called power point) (Fig. 6). For the phloxin B-EDTACTAB system the power point was $66.72 \mu \mathrm{W}$. The performance of the cell, i.e. the storage capacity (denoted by $\mathrm{t}_{1 / 2}$ ) was observed for 100 minutes by keeping the cell at the power point stage in dark and noting the time required for power output to fall to its half value (Fig. 7).

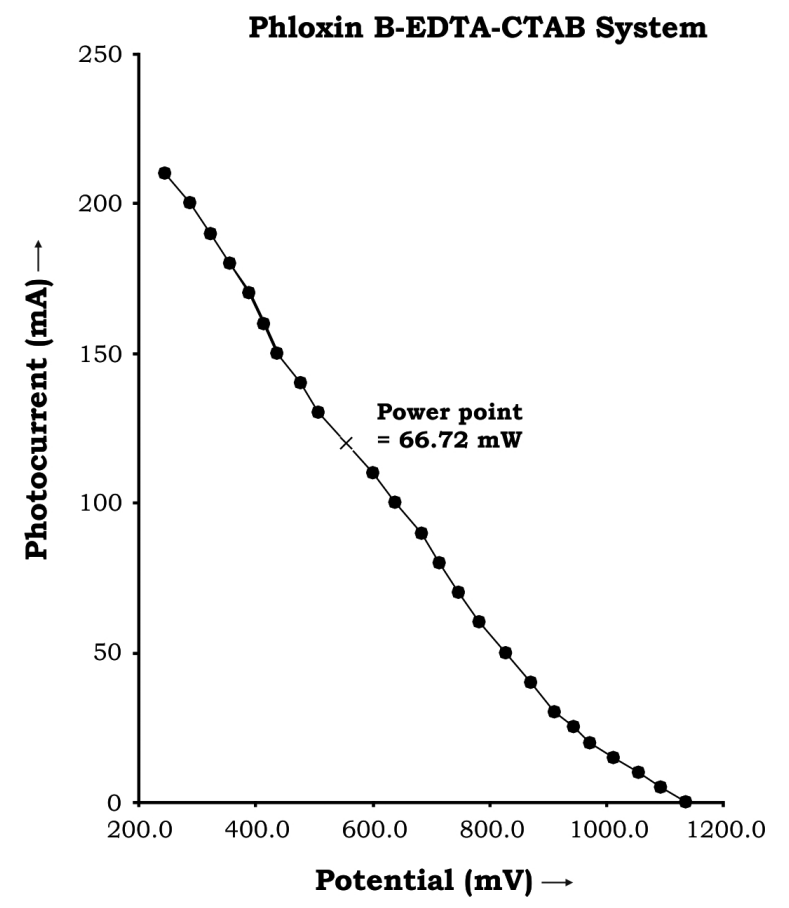

Fig. 6. Current-voltage curve.

The conversion efficiency and fill factor of the cell (with platinum foil electrode of $1 \mathrm{~cm}^{2}$ ) were 
Table 4. Effect of variation of electrode area.

\begin{tabular}{ccc}
\hline Electrode area $\left(\mathrm{cm}^{2}\right)$ & $\begin{array}{c}\text { Maximum photocurrent } \\
\mathrm{I}_{\max }(\mu \mathrm{A})\end{array}$ & $\begin{array}{c}\text { Equilibrium photocurrent } \\
\mathrm{I}_{\mathrm{eq}}(\mu \mathrm{A})\end{array}$ \\
\hline \hline 0.55 & 285.0 & 276.0 \\
0.70 & 290.0 & 270.0 \\
0.85 & 295.0 & 265.0 \\
1.00 & 300.0 & 260.0 \\
1.15 & 305.0 & 255.0 \\
1.30 & 310.0 & 249.0 \\
1.45 & 315.0 & 243.0 \\
\hline [phloxin B] $=4.4 \times 10^{-4} \mathrm{M}$ & & Light intensity $=10.4 \mathrm{~mW} \cdot \mathrm{cm}^{-2}$ \\
{$[$ EDTA $]=2.20 \times 10^{-3} \mathrm{M}$} & $\mathrm{Temp}=303 \mathrm{~K}$ \\
{$\left[\right.$ CTAB] $=1.5 \times 10^{-3} \mathrm{M}$} & $\mathrm{pH}=12.64$
\end{tabular}

Table 5. Effect of variation of light intensity.

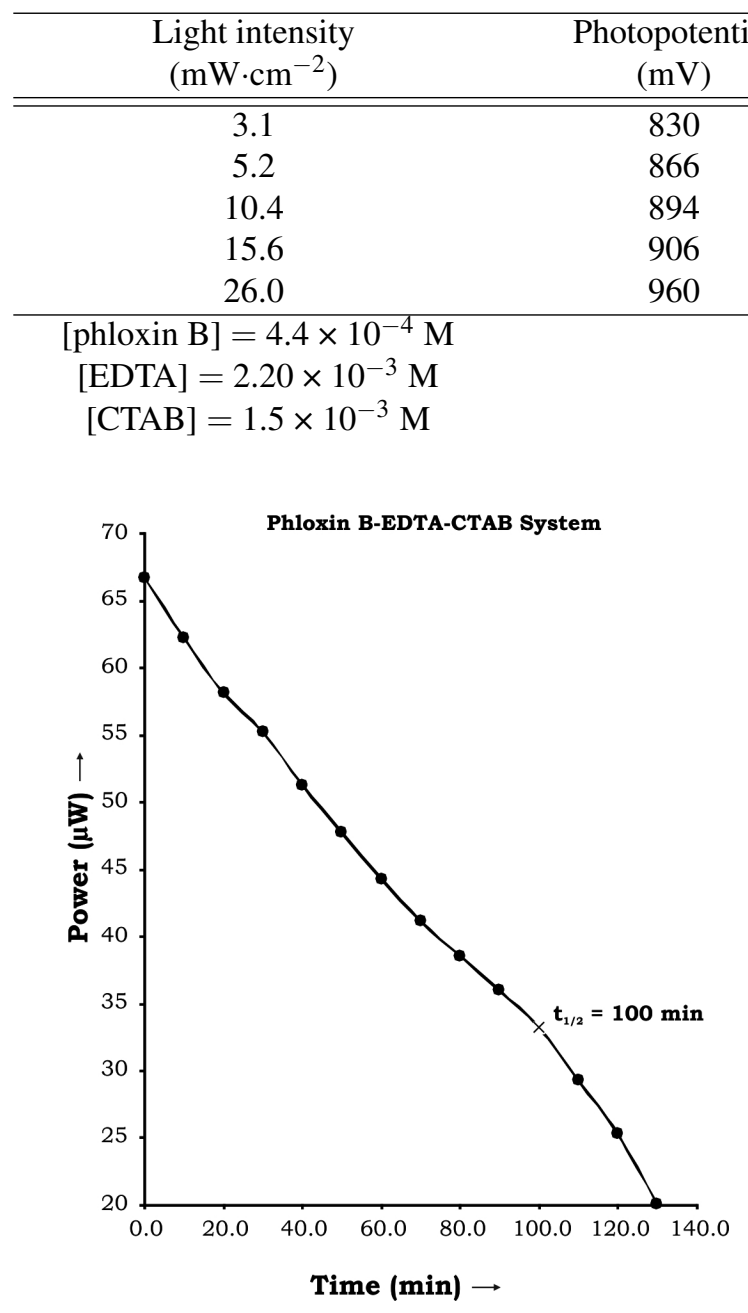

Fig. 7. Time-power curve.

determined as $0.64 \%$ and 0.2261 , respectively, by the following formula:
Conversion efficiency:

$\mathrm{V}_{\mathrm{pp}} \times \mathrm{i}_{\mathrm{pp}} / \mathrm{A} \times 10.4 \mathrm{~mW} / \mathrm{cm}^{2} \times 100 \%$

Fill factor:

$\mathrm{V}_{\mathrm{pp}} \times \mathrm{i}_{\mathrm{pp}} / \mathrm{V}_{\mathrm{oc}} \times \mathrm{i}_{\mathrm{sc}}$

where $V_{p p}$ and $i_{p p}$ represent the value of potential and current at power point, respectively.

\section{Conclusion}

Photogalvanic cell using phloxin B/EDTA/CTAB have been successfully fabricated. The maximum value of photocurrent and photopotential, obtained in the present work, were $300.0 \mu \mathrm{A}$ and $1135.0 \mathrm{mV}$, respectively. The efficiency of the cell depended on the dye-surfactant combination. For further improvement of performance of the photogalvanic cell, the selection of efficient dye-surfactant combination in maximum coverage of light radiation (solar spectrum) is necessary. 


\section{Acknowledgements}

The Authors are thankful to the Head of Department of Chemistry, J.N.V. University, Jodhpur, for providing necessary facilities. One of the Authors (Shraddha) is grateful to the University Grant Commission, New Delhi, for providing financial assistance under the scheme of UGC-RGNF (F.1-17.1/2012-13/RGNF-2012-13-SC-RAJ18022)/(SA-III).

\section{References}

[1] Rideal E.K., Williams E.G., J. Chem. Soc. Trans., 127 (1925), 258.

[2] Rabinowitch E., J. Chem. Phys., 8 (1940), 551.

[3] Rabinowitch E., J. Chem. Phys., 8 (1940), 560.

[4] BAyer L.S., EROGle I.,TURKer L., Int. J. Eneg. Res., 25 (2001), 207.

[5] Markov P., Novkirishika Rabinowitch E., $J$. Chem. Phys., 8 (1940), 560.

[6] Bayer L.S., Erogle M., Alijanapy K., J. Photoch. Photobio. A, 96 (1996), 161.

[7] Markov P., NovkirishKa M., Electrochim. Acta, 36 (1991), 1287.

[8] JANA A.K., J. Photoch. Photobio. A, 132 (2000), 1.
[9] Hamdi S.T., Aliwi S.M., Monatsh. Chem., 127 (1996), 339.

[10] Gangotri K.M., Bhimwal M.K., Energ. Source. Part A, 23 (2011), 2058.

[11] Gangotri K.M., Solanki P.P., Sol. Energy, 85 (2011), 3028.

[12] Ameta S.C., Khamesra S., Chittora A.K., GanGOTRI K.M., Int. J. Energ. Res., 13 (6) (1989), 643.

[13] Koli P., Sharma U., Gangotri K.M., Renew. Energ., 37 (2012), 250.

[14] Koli P., Appl. Energ., 118 (2014), 331.

[15] Genwa K.R., Chouhan A., Energ. Source. Part A, 35 (2013), 685.

[16] Genwa K.R., Sagar C.P., Int. J. Phys. Sci., 8 (2013), 1515.

[17] Genwa K.R., Singh K., Smart Grid Renew. Energ., 4 (2013), 306.

[18] Genwa K.R., Sagar C.P., Energ. Convers. Manage., 66 (2013), 121.
Received 2015-03-01

Accepted 2015-06-09 